\title{
Pengaruh Metode Latihan Acceleration Sprint terhadap Kemampuan Lari 60 Meter Siswa
}

\author{
Yulmardani Yulmardani
}

Sekolah Dasar Negeri 03 Pancung Tebal Kecamatan Bayang Utara

\begin{abstract}
The problem in this study is the ability to run 60 meters Class V SDN 03 Pancung Tebal North Bayang District because 60 meters running are not in accordance with the time that should be achieved by junior-high-school students. Many factors cause the 60-meter running ability is not good, including the training method. For this reason, it is necessary to conduct a study with the aim to find out how much influence the acceleration sprint training method has on the ability to run 60 meters Class V SDN 03 Pancung Thick Bayang Utara District. This type of research is quasi-experimental. The study population was students of Class V SDN 03 Pancung Tebal District of North Bayang. Samples using purposive sampling technique, namely sampling based on the intentions that have been determined previously or with certain considerations, amounting to 15 people aged 11-13 years. Data was collected using a 60-meter student test with a 60-meter running ability test. The data analysis technique is the T-Test. The results of the data analysis show that: There is a significant influence on the acceleration sprint exercise of the ability to run $60 \mathrm{~m}$ Grade V students of SDN 03 Pancung Tebal, North Bayang District.
\end{abstract}

Keywords: acceleration sprint

This is an open access article distributed under the Creative Commons Attribution License, which permits unrestricted use,
distribution, and reproduction in any medium, provided the original work is properly cited. (C2019 by author

\section{PENDAHULUAN}

Perkembangan dan kemajuan ilmu pengetahuan dan teknologi pada masa sekarang ini sangat memberi perubahan-perubahan diberbagai bidang ilmu pengetahuan, termasuk perubahan dalam bidang olahraga. Dengan kemajuan ilmu pengetahuan dan teknologi para pakar olahraga banyak menemukan penemuan-penemuan baru, baik itu dari segi teorinya mengenai teknik-teknik maupun dalam bentuk peralatan yang canggih yang sangat menunjang dan berguna untuk meningkatkan prestasi dalam olahrga.Atletik pada nomor lari $60 \mathrm{~m}$ juga merupakan bagian dari kurikulum di sekolah, materi lari $60 \mathrm{~m}$ digunakan sebagai bahan ajar guna mencapai tujuan pelajaran penjas yaitu untuk meningkatkan kesegaran jasmani di sekolah. Disamping itu dengan mempelajari penjas diharapkan wawasan dan pengetahuan siswa tentang olahraga secara teori bertambah. Bukan itu saja, tidak kalah pentingnya adalah bagaimana siswa dapat melakukan gerakan-gerakan dalam cabang olahraga khususnya atletik pada nomor lari $60 \mathrm{~m}$.

Untuk meraih prestasi atletik khususnya lari 60 meter maka siswa Kelas V SDN. 03 Pancung Tebal Kecamatan Bayang Utara telah berlatih untuk nomor lari 60 meter, namun fasilitas dan metode latihan yang belum tepat sehingga kemampuan lari 60 meter siswa SDN. 03 Pancung Tebal Kecamatan Bayang Utara belum maksimal hal ini tentunya berdampak pada siswa yang prestasinya menurun. Banyak faktor yang menentukan kemampuan lari sprint meter bagi seorang pelari diantaranya, program latihan, metode latihan, kemampuan pelatih, gizi atlet, sarana dan prasarana, kemampuan fisik, minat dan bakat. Disamping itu lari 60 meter yang sangat menuntut kecepatan juga tergantung pada beberapa faktor sebagaimana yang diungkapkan oleh Pate dalam Arsil (85:1999) bahwasanya "kecepatan itu dipengaruhi oleh beberapa faktor yaitu, 1) tipe otot, 2) koordinasi neuromuscular, 3) biomekanik, 4) kekuatan otot".

Seluruh aspek latihan tersebut hendaknya diterapkan pada seluruh siswa sprint agar memiliki kemampuan lari 60 meter yang baik. Namun sayangnya belum semuanya siswa yang mampu menerapkanya, terutama siswa- 
siswi yang mengikuti kegiatan SDN. 03 Pancung Tebal Kecamatan Bayang Utara. Salah satu penyebabnya yang sangat terlihat adalah belum pasnya bentuk latihan yang tepat dalam meningkatkan prestasi lari 60 meter SDN. 03 Pancung Tebal Kecamatan Bayang Utara. Karena latihan menurut Darwis (1999) "sangat penting untuk dipergunakan dalam memperbaiki elemen-elemen teknik baik secara terpisah maupun dikombinasikan, dimana proses latihan berlangsung sama dari awal sampai akhir". Bentuk latihan yang dapat digunakan dalam meningkatkan kecepatan lari 60 meter adalah kemampuan bersyarat untuk menghasilkan gerakan tubuh dalam keadaan atau waktu yang sesingkat mugkin.

Kecepatan merupakan salah satu unsur penting pada beberapa cabang olahraga tertentu, seperti: atletik pada nomor lari, sepak bola, renang, dan sebagainya. Sedangkan menurut Jonath dan Kerempel dalam Syarifuddin (1999: 43) mengemukakan "Kecepatan adalah secara fisiologi diartikan sebagai kemampuan untuk melakukan gerakan dalam suatu satuan tertentu yang ditentukan oleh fleksibelitas tubuh, proses sistem persyarafan dan kemampuan otot".Dibidang Olahraga Atletik kemampuan siswa menurun terutama dalam Lari 60 M. Dari permasalahan di atas maka peneliti tertarik untuk melakukan penelitian tentang "Pengaruh Latihan Acceleration Sprint terhadap Kemampuan Lari 60 M Siswa Kelas V SDN. 03 Pancung Tebal Kecamatan Bayang Utara".

\section{METODE}

Penelitian ini menggunakan eskperimen semu untuk mengetahui pengaruh metode latihan acceleration sprint terhadap lari 60 m siswa Kelas V SDN 03 Pancung Tebal Kecamatan Bayang Utara. Populasi dalam penelitian ini adalah siswa Kelas V SDN 03 Pancung Tebal Kecamatan Bayang Utara, yang berjumlah15 putraputri yang melakukan kegiatan dengan rincian yaitu: 11 orang siswa putra dan 4 orang siswi putri yang umurnya kisaran 12-13 tahun. Sampel dalam penelitian ini adalah siswa SDN 03 Pancung Tebal Kecamatan Bayang Utara yang mengikuti kegiatan lari 60 m yang berjumlah 15 orang, yaitu siswa putra-putri. Penentuan atau pelaksanaan latihannya dilakukan latihan sebanyak 16 kali pertemuan dengan frekuensi 3 kali dalam seminggu dan lama waktu latihan setiap latihan lebih kurang adalah 50 menit, latihan baru akan memberikan efek setelah 6 minggu dan dilakukan 3 kali dalam seminggu. Kemudian data dianalisis dengan menggunakan statistik inferensial, melalui uji beda yaitu $t$ test.

\section{HASIL PENELITIAN}

\section{Deskripsi Data}

Data penelitian ini terdiri dari: Kemampuan Lari 100 Meter (Y) sebagai variabel terikat, Metode Latihan Acceleration Sprint $\left(\mathrm{X}_{1}\right)$ sebagai variabel bebas. Untuk masing-masing variabel di bawah ini akan disajikan nilai rata-rata, simpangan baku, median, distribusi frekuensi, serta histogram dari setiap variabel.

\section{Deskripsi Data Kemampuan Lari $100 \mathrm{M}$}

a. Pre test

Berdasarkan data penelitian untuk skor kecepatan, didapatkan data bahwa skor tertinggi 20,3 dan skor terendah 15,09. Dari analisis data diperoleh harga rata-rata (Mean) sebesar 17,52, Simpangan baku (standar deviasi) 1,48, dan Median 17,5. Distribusi frekuensi kemampuan lari 100 meter sebagaimana tampak pada Tabel berikut ini:

Tabel. 4

Distribusi Frekuensi Data Kemampuan Lari 100 M Pretest

\begin{tabular}{cccc}
\hline No. & Kelas Interval & Frekuensi Absolut & Frekuensi Relatif $(\%)$ \\
\hline $\mathbf{1 .}$ & $15,09-16,17$ & 3 & 20 \\
$\mathbf{2 .}$ & $16,18-17,26$ & 4 & 26,6 \\
$\mathbf{3 .}$ & $17,27-18,35$ & 4 & 26,6 \\
$\mathbf{4 .}$ & $18,36-19,44$ & 1 & 6,6 \\
$\mathbf{5 .}$ & $19,45-20,53$ & 3 & 20 \\
& Total & 15 & 100 \\
\hline
\end{tabular}

Berdasarkan perhitungan yang tertera pada Tabel 1 dapat dilihat bahwa: 3 orang atau (20\%) berada pada kelas interval $15,09-16,17,4$ orang atau $(26,6 \%)$ berada pada kelas interval 16,18-17,26, 4 orang atau 
$(26,6 \%)$ berada pada kelas interval $17,27-18,5,1$ orang atau $(6,6 \%)$ berada pada kelas interval $18,36-$ $19,44,3$ orang atau (20\%) berada pada kelas interval 19,45-20,53.

\section{b. Post Test}

Berdasarkan data penelitian untuk skor kemampuan lari 100 M, didapatkan data bahwa skor tertinggi 19 dan skor terendah 13,84. Dari analisis data diperoleh harga rata-rata (Mean) sebesar 16,78, Simpangan baku (standar deviasi) 1,49, dan Median 17. Distribusi frekuensi kemampuan lari $100 \mathrm{~m}$ sebagaimana tampak pada Tabel 5 berikut ini:

Tabel. 5

Distribusi Frekuensi Data Kemampuan Lari 100 M Post tes

\begin{tabular}{cccc}
\hline No. & Kelas Interval & Frekuensi Absolut & Frekuensi Relatif $(\%)$ \\
\hline 1. & $13,84-14,89$ & 3 & 20 \\
2. & $14,90-15,95$ & 0 & 0 \\
3. & $15,96-17,01$ & 6 & 40 \\
4. & $17,02-18,07$ & 4 & 26,6 \\
5. & $18,08-19,13$ & 2 & 13,3 \\
& Total & 15 & 100 \\
\hline
\end{tabular}

Berdasarkan perhitungan yang tertera pada Tabel 5 dapat dilihat bahwa: 3 orang atau (20\%) berada pada kelas interval 13,84-14,89, 0 orang atau $(0 \%)$ berada pada kelas interval 14,90-15,95, 6 orang atau $(40 \%)$ berada pada kelas interval 15,96-17,01, 4 orang atau (26,6\%) berada pada kelas interval 17,02-18,07, 2 orang atau $(13,3 \%)$ berada pada kelas interval 18,08-19,13.

\section{Pengujian Persyaratan Analisis}

Persyaratan analisis yang dimaksud adalah persyaratan yang harus dipenuhi sebelum melakukan analisis korelasi. Persyaratan analisis tersebut meliputi Uji Normalitas yaitu sebagai berikut:

\section{Uji Normalitas}

Hasil analisis uji normalitas data masing-masing variabel di sajikan dalam tabel di bawah ini :

Tabel 6. Uji normalitas dengan Lilifours

\begin{tabular}{|c|c|c|c|}
\hline & \multicolumn{2}{|c|}{ Uji Lilifours } & \multirow[t]{2}{*}{ Kesimpulan } \\
\hline & $\mathrm{L}_{\mathrm{o}}$ & $\mathrm{L}_{\text {tabel }}$ & \\
\hline Kemampuan Lari $100 \mathrm{M}$ & 0,1234 & 0,2200 & Normal \\
\hline
\end{tabular}

Tabel 4 di atas menunjukkan bahwa hasil pengujian untuk Kemampuan lari 100 meter (Y) adalah 0,1234 dengan probabilitas (sig.) 0,2200. Dengan $\alpha>0,05$, maka dapat disimpulkan bahwa data berdistribusi normal. Berdasarkan uraian di atas semua variabel $\mathrm{Y}$ datanya berdistribusi normal, karena masing-masing variabel probabilitasnya memenuhi kriteria $\mathrm{L}_{\mathrm{o}}<\mathrm{L}_{\text {Tabel }}$. Hal ini dapat dikatakan bahwa data masing-masing tersebar secara normal atau populasi dari data sampel diambil berdistribusi normal.

\section{Pengujian Hipotesis}

Setelah uji persyaratan analisis dilakukan dan ternyata semua skor tiap variabel penelitian memenuhi persyaratan untuk dilakukan pengujian statistik lebih lanjut, maka selanjutnya dilaksanakan pengujian hipotesis. Dalam penelitian ini ada tiga hipotesis penelitian, yaitu: (1) Terdapat pengaruh yang berarti antara pengaruh latihan acceleration sprint terhadap kemampuan lari 100 m Siswa Kelas V SDN 03 Pancung Tebal Kecamatan Bayang Utara. Berikut ini disajikan hasil pengujian terhadap hipotesis penelitian yang telah diajukan di atas.Terdapat pengaruh yang berarti antara pengaruh latihan acceleration sprint terhadap kemampuan lari $100 \mathrm{~m}$ Siswa Kelas V SDN 03 Pancung Tebal Kecamatan Bayang Utara.Analisis Uji T terhadap variabel metode latihan acceleration sprint dengan kemampuan lari $100 \mathrm{~m}$ Siswa Kelas V SDN 03 Pancung Tebal Kecamatan Bayang Utara. menghasilkan uji $\mathrm{t}$ sebesar $\mathrm{t}$ hit $=12,93$, dan $\mathrm{t}$ tabel $=1,761$. Untuk lebih jelasnya dapat dilihat rangkuman hasil analisis Tabel 5 berikut ini. 
Tabel 7.

Rangkuman Hasil Analisis antara Variabel latihan Acceleration Sprint (X1) dan Kemampuan Lari 100 M (Y)

\begin{tabular}{cccc}
\hline Data & N & t-hitung & t-tabel $\boldsymbol{\alpha} \square=\mathbf{0 , 0 5}$ \\
\hline Kemampuan Lari 100 Meter & 15 & 12,93 & 1,761 \\
\hline
\end{tabular}

Hipotesis pertama diketahui bahwa yang diajukan Ha dapat diterima. Hal ini dapat diketahui dimana $\mathrm{t}$ hit $=$ $12,93>\mathrm{t} t \mathrm{tab}=1,761$. Sehingga disimpulkan bahwa Terdapat pengaruh yang berarti antara pengaruh latihan acceleration sprint terhadap kemampuan lari 100 m Siswa Kelas V SDN 03 Pancung Tebal Kecamatan Bayang Utara.

\section{PEMBAHASAN}

Berdasarkan hasil analisis data $\mathrm{t}$ hit $=12,93>\mathrm{t}$ tab $=1,761$. Sehingga disimpulkan bahwa Terdapat pengaruh yang berarti antara pengaruh latihan acceleration sprint terhadap lari $100 \mathrm{~m}$ Siswa Kelas V SDN 03 Pancung Tebal Kecamatan Bayang Utara. Ini menegaskan bahwa untuk memperoleh kemampuan lari 100 meter yang maksimal dibutuhkan latihan acceleration sprint yang baik. Atletik adalah aktivitas jasmani yang kompetitif, meliputi beberapa nomor lomba yang terpisah berdasarkan kemampuan gerak manusia seperti, berjalan, berlari, lompat, dan lempar" (PB PASI 1993:01). Pada awal mula terbentuk atletik yang mulai terorganisasi umumnya diakui telah terjadi sejak zaman yunani kuno dan dikenal dalam olympiade purba.

Lari jarak pendek (sprint) adalah lari yang menempuh jarak antara 100 meter sampai dengan 400 meter (Yoyo Bahagia, dkk, 2000: 9-10). Lari sprint 100 meter merupakan nomor lari jarak pendek, dimana pelari harus berlari dengan sekencang-kencangnya dalam jarak 100 meter. Kunci pertama yang harus dikuasai oleh pelari cepat atau spint adalah start. Keterlambatan atau ketidaktelitian pada waktu melakukan start sangat merugikan seorang pelari cepat atau sprinter. Oleh sebab itu, cara melakukan start yang baik harus benar-benar diperhatikan dan dipelajari serta dilatih secermat mungkin. Kebutuhan utama untuk lari jarak pendek adalah kecepatan horizontal, yang dihasilkan dari dorongan badan ke depan.Lari adalah lompatan yang berturut-turut di dalamnya terdapat suatu fase dimana kedua kaki tidak menginjak atau menumpu pada tanah (PASI, 1987:25). Sedangkan menurut Jonath dan Kerempel dalam Syarifuddin (1999: 43) mengemukakan "Kecepatan adalah secara fisiologi diartikan sebagai kemampuan untuk melakukan gerakan dalam suatu satuan tertentu yang ditentukan oleh fleksibelitas tubuh, proses sistem persyarafan dan kemampuan otot”.

Kecepatan juga diartikan sebagai kemampuan seseorang untuk melakukan gerak dalam waktu sesingkatsingkatnya. Kecepatan merupakan salah satu unsur penting pada beberapa cabang olahraga tertentu, seperti atletik pada lompat jauh, sepak bola, renang, dan sebagainya. Kecepatan adalah kemampuan untuk menempuh suatu jarak dalam waktu secepatnya. Menurut Bafirman (2008: 100) Kecepatan adalah "merupakan kemampuan tubuh mengarahkan semua sistemnya dalam melawan beban, jarak dan waktu yang menghasilkan kerja mekanik".

\section{KESIMPULAN}

Berdasarkan hasil penelitian yang telah diuraikan pada bab terdahulu dapat dikemukakan kesimpulan sebagai berikut: Terdapat pengaruh yang berarti antara pengaruh latihan acceleration sprint terhadap kemampuan lari 100 m Siswa Kelas V SDN 03 Pancung Tebal Kecamatan Bayang Utara, dengan t hit = 12,93> $\mathrm{t} \mathrm{tab}=1,761$.

\section{DAFTAR RUJUKAN}

Agus, Apri \& Bafirman. (2008). Pembentukan Kondisi Fisik. Padang: FIK UNP

Arsil. (2009). Tes pengukuran dan Evaluasi. Padang: FIK UNP

Buku Pedoman Akademik. (2009). Padang: FIK UNP

Ahady.(1989). Pengantar Pengetahuan Kurikulum. Padang: FPOK IKIP

Garry A. (2003). Atletik untuk sekolah. Jakarta 
Lutan, Rusli. (1987). Pengelolaan interaksi belajar mengajar intrakurikuler sebagai salah satu pembinaan kesiswaan. Jakarta: UI - Press

PB PASI. (1981). Cara mengajar lari. Jakarta: Direktoral Jendral Olahraga dan Pemuda.

Syafruddin. (1999). Dasar-dasar kepelatihan Olahrga. Padang: FIK UNP

Syafruddin. (2012). Dasar-dasar kepelatihan Olahrga. Padang: FIK UNP.

Tim Atletik. (2004). Atletik Dasar. Padang: FIK UNP

UUD SKN.(2005). Undang-undang Repoeblik Indonesia No. 3 tahun 2005 Peraturan Pemerintah tentang dasar dan fungsi dan tujuan olahraga

Ahady.(1989). Pengantar Pengetahuan Kurikulum. Padang: FPOK IKIP

Harsono . (1988). Coaching dan Aspek Psikologi dalam Coaching. Jakarta, Depdikbut Dirijen Dikti P2tk

Suharsimi, Arikunto (2006). Prosedur Penelitian Suatu Pendekatan Praktik. Jakarta: Rineka Cipta 